\title{
The Principles of European Insurance Contract Law: the Duty of Disclosure and the Aggravation of Risk
}

\author{
Herman Cousy
}

Published online: 20 August 2008

(C) ERA 2008

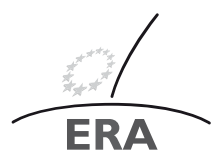

EUROPÄISCHE RECHTSAKADEMIE ACADEMY OF EUROPEAN LAW ACADEMIE DE DROIT EUROPEEN ACADEMIE DE DROHT EUROPEEN TRIER - TREVES - TREVIRI

\section{The Context}

The task of this article is to provide some commentary on two well-known subjects of insurance contract law which are dealt with in the Principles of European Insurance Contract Law. There is no necessary connection between the two subject matters, although in many national legal systems they are linked.

The first topic is the well known problem of the pre-contractual duty on the applicant to provide information (i.e., the duty of disclosure or 'l'obligation de déclaration du risque'). The second topic is the change of the degree or level of risk in the course of the lifetime of the contract, a subject matter which is mostly addressed from the angle of the 'aggravation' of the insured risk, and which is often thought to be another aspect of the policy-holder's information-providing duty, which is supposed to extend beyond the moment of the conclusion of the contract. It is proposed to begin by discussing the pre-contractual information duties of the applicant.

No lengthy explanations are needed in order to convince anyone of the importance which this issue has always had in the development of insurance contract law, of its importance in the day-to-day practice of insurance litigation, and of the continuing pivotal role that this issue plays in new laws concerning insurance contracts. The practical importance of the subject matter is emphasised here because in the past the issue of 'réticences et fausses déclarations' has played an important role in so much case-law between parties to insurance contracts. One cannot but observe with

Prof. Dr. Herman A. Cousy $(\bowtie)$

Katholic University Leuven, Faculty of Law

Tiensestraat 41, 3000 Leuven, Belgium

e-mail: Herman.Cousy@law.kuleuven.ac.be

This article originated as an oral presentation on the subject matter at the occasion of the conference European Insurance Contract Law and the Common Frame of Reference, which was organised by ERA in cooperation with the Joint Network on European Private Law, and took place in Trier on 21-22 January, 2008. The author has retained some of the characteristics of this presentational form, including avoiding the addition of a large body of footnotes. 
a certain degree of amazement how very often shortcomings in fulfilling this duty and misrepresentations used to be raised as a defence by the insurer at the moment when a claim was brought against it. There is probably some truth to the statement that the moment where a claim is brought is the 'moment suprême' in the intimate relationship between insurer and insured, i.e., the moment where the parties learn to find out what the other party is really like. Indeed, the impression has grown that in many instances risks came to be examined by the insurer thoroughly only at the time when claims arose. It also remains true that the old regime with its radical sanctions was quite harsh on the policy-holder. It is understandable that many legislatiors have judged the old regime to be unjust and severe to the point of requiring radical, or at least profound changes of the rules.

The first characteristic of the traditional regime concerning the duty of disclosure was that it laid on the applicant the duty to declare spontaneously the characteristics of the risk. This system of 'spontaneous declaration' would later be considered to put an unreasonable burden on the applicant who is almost always a layman in matters of risk appreciation. In many legal systems, the old rule has recently been replaced by the system of a list of questions, the 'questionnaire'.

A second major characteristic of the old system was the use of the 'all or nothing' principle in the way in which violations of the duty of disclosure were sanctioned. Under this 'Alles oder nichts Prinzip' approach a violation of the duty of declaration led to the loss of the entire cover - even if the shortcoming was minor, and notwithstanding the absence of any correlation whatsoever between the undeclared circumstance and the insured event. In several national legal systems, the rule has been changed in the sense that the 'all or nothing' principle has been replaced by a reduction of the insurance payment, in proportion to the effect of the undisclosed circumstance upon the risk calculus of the insurer.

Under the old regime, in its most extreme formulation, violations of the duty of disclosure were considered to lead to a defect affecting the consent of the parties to the contract ('vice de consentment') and thus the validity of the contract. This reference to the validity requirements of the contract explains why the sanction for failure to describe fully and correctly the insured risk was sought in the nullity of the contract. Here again, recent legislation has abandoned this view and replaced this 'validity of contract' approach with another more economical one, based on the equilibrum between the real risk and the amount of the price. Except in the cases of fraud, a failure to disclose will not lead to the avoidance of the contractual relationship but will be so conceived as to enable the continuation of the contract whenever possible, accompanied by an adaptation of the premium on the basis of a new agreement between the parties.

A second introductory observation and remark are apposite here about the broader context in which our Principles of European Insurance Contract Law, and in particular the new rules on the duty of disclosure, have come into being. One must be aware of the fact that in relation to this issue, as on many other vital issues of insurance contract law, an impressive amount of legislative activity has seen the light of day in the course of very recent years. Legislative changes and renewals of insurance contract law have been such as to make efforts to 'restate' or 'harmonise' these rules very difficult indeed ${ }^{1}$ for the time being.

1) For an overview, see my contribution, Cousy [4]. 
In the Max Planck comparative study on the insurance contract law of a number of European national systems published by Basedow and Fock in $2002^{2}$, the authors could still safely observe that the 'spontaneous duty of declaration' was the prevailing rule in a large number of member states, among them Belgium, Italy, Luxemburg, the United Kingdom and Ireland, and even Germany (although in this last case, the severity of the rule has been seriously reduced by corrections introduced by case law). Since then, things have changed rapidly in most European member states. Considerable impetus for change was provided by the 1979 proposed EEC directive ${ }^{3}$, in which the concepts of proportional reduction and continuity of the contract (instead of avoidance) were put forward as techniques to deal with breaches of the duty of disclosure. In a number of national legal systems, the duty of spontaneous declaration would subsequently be abandoned, or at least softened, by putting the burden of identifying the relevance of the information to be transferred upon the insurer. This writer considers the introduction of the requirement of 'causality' (or relevance) as a very important change in insurance contract law. This new rule - which has now found its way into the new Dutch Burgerlijk Wetboek (Article 930 (7.17.1.6)) and also into the new German Insurance Contract Law - constitutes a radical breach with the old and traditional rule according to which a failure to describe adequately a risk could lead to a reduction of the coverage of a claim, even if the undisclosed fact or circumstances had no relevance whatsoever to the occurrence of the insured event. Under the new 'causality' rule the philosophy is different. Here a failure to the duty of disclosure will not give rise to a reduction of the payment either if the undisclosed or ill-disclosed facts are not material to the assessment of the risk as it has materialised (the approach of Article 930 of the Dutch Civil Code) or else if the failure to the duty of disclosure relates to a circumstance which is in a causal relationship either with the occurrence or the discovery of the insured event, or with the existence or extent of the insurer's duty to cover (the approach of German insurance law).

English law can also be mentioned as an illustration of the changing legal context since even here a change in the fundamental aspects of the duty of disclosure may possibly also come about, going by the (Joint) Consultation Paper No. 182 of the Law Commission (which is simultaneously Discussion Paper No. 134 of the Scottish Law Commission) Insurance Contract Law: misrepresentation, non-disclosure and breach of warranty by the insured. Already under the present state of the law, according to the Law Commission, consumers benefit from a certain degree of protection against the strict effects of the law. They do so by virtue of the effect of not one, but several 'codes of conduct' like the Insurers' Statements of Practice, the rules of conduct issued by the Financial Services Authority, and the dispute resolution practices by the Financial Ombudsman Service, which exist over and above the stricter rules of law. The existence of these different systems of law, regulation and guidance is considered by the Law Commission to have produced an unclear and inaccessible set of rules for both insurers and consumers. The Law Commission therefore proposes a law reform that would make a clear distinction between a mandatory regime for

\footnotetext{
2) Basedow/Fock [3], p. 108.

3) Proposal for a directive of 10 July 1979 of the Council as modified by the proposal for a directive of 30 December 1980 (OJ C 355 of 31 December 1980). The proposal was later on officially withdrawn (OJ C 228 of 24 August 1993, p. 14).
} 
consumers (based on Financial Ombudsman Service practice), and a default regime ${ }^{4}$ for business, based on accepted good pratice. As regards pre-contractual information provided by the insured in consumer contracts, the Law Commission proposes to replace a consumer's duty to volunteer information with a requirement to answer questions carefully and honestly. Deliberately and recklessly giving incorrect answers would entitle the insurer to avoid the policy and refuse all claims under it. In the event of negligence from the side of the consumer, the insurer should be put in a position, in which he would have been if he had been aware of the full facts. This means proportional reduction of the claim if the insurer would have charged more; no payment of a claim that the insurer would have excluded; and the right of the insurer to avoid the policy (although with the return of premiums paid) if he would have declined the risk altogether.

Another item in the Law Commission's proposal, which presents not a direct, but quite clearly an indirect link with the present subject matter, merits mention - viz., the Law Commission's proposal concerning the role of brokers and other intermediaries. The Law Commission proposes to clarify that 'tied agents', who sell the products of a limited range of insurers should be treated as acting for the insurer, while intermediaries who are clearly independent should be considered to be acting for the policy-holder 5 . There is no need to stress the importance of the role that intermediaries play in practice to the way in which applicants for insurance fulfil their duty of disclosure. Indeed, the above-mentioned proposed difference in the treatment of tied agents and independant intermediaries is symptomatic of what is happening in a growing number of European member states.

At this point, a number of recent developments and tendencies which relate to pre-contractual duties to inform may be recalled, whereby some other interesting and important issues are raised besides those that have been mentioned above.

In many contracts, the practical effect of failures to comply with a duty of disclosure is diminishing because of the existing tendency to include so-called 'clauses d'incontestabilité' in a growing number of contracts, either voluntarily or by virtue of a compulsory rule of law. The reasons why such clauses are deemed useful are either practical (in life insurance, where 'incontestabilité' is imposed by law because of the difficulty of discovering failures in the initial applicant's declarations after long periods of time) or socially-inspired (e.g., in private health insurance contracts). A striking example of this last category is the recent Belgian Act of 20 July 2007 concerning (private) complementary health insurance, introducing into the 'Loi du contrat d'assurances terrestres' of 25 June 1992, amongst others, a new article 138 bis-5, which (in a highly ambiguous formulation) says that after a period of two years, the (private) health insurer cannot rely on a (non-intentional) failure on the part of the applicant to declare any illness or disorder that had manifested itself at the time of conclusion of the contract, but was not diagnosed before this two year period.

\footnotetext{
4) For 'continental' lawyers: a set of rules that apply in the absence of derogatory stipulations in the contract by the parties.

5) The Commission 'asks' whether the test on the intermediary's independence should be whether the intermediary has made a "fair analysis" of the market, as defined in the Insurance Mediation Directive 2002/92/EC of 9 december 2002 (OJ L 9 of 15 January 2003, p. 3).
} 
Another remarkable feature which is often found in recent national legislative provisions and which also leads to a restriction of the extent of the applicant's duty of disclosure, is where the law prohibits the exchange of specific items of information, in spite of the fact that such information is highly relevant to an appreciation by the insurer of the level of risk. The best known example is the prohibition, by many legislative provisions, of the search for, transfer to or use by the insurer of genetic information. The motivation for such prohibition of the use of genetic information is found in various sources, such as the protection of privacy, the protection of human dignity, or in motives of non-discrimination. The result of such exclusion of genetic information is the socialisation of the genetic risk, i.e., the equal spreading of the costs over the entire insured population, inspite of the fact that the risks are very unequally spread. Banning the transfer of genetic information leads to a subsidisation of 'genetically unlucky' individuals by 'genetically lucky' individuals.

Anti-discrimination laws in general, insofar as they prohibit the demand for and/ or the taking into account of information about the 'sensitive' (i.e., discriminatory) characteristics of the insurance risk, equally have a redistributive effect. An example which is well known in the field of life insurance and personal insurance, is the case of 'gender discrimination'. As is well-known, the recent EC directive on gender discrimination $^{6}$ prohibits premium segmentation based on gender but allows member states to opt out of the system of the directive (a possibility of which nearly all member states have made use). In today's society the tendency toward socialisation of risks (whether through cutting off risk-information transfer, or otherwise) is a paradoxical phenomenon, inasmuch as it is opposed to the other major tendency of insurance practice of striving to differentiate between risks and segment premium tariffs, such differentiation being one of the prime characteristics of a competitive insurance environment. In order to differentiate adequately, the insurer needs a reliable and detailed picture and thus precise information about all relevant characteristics of the risk. Non-discrimination law bluntly prevents the insurer from acquiring information about, and taking into account, a number of relevant yet sensitive characteristics of the risk being insured against.

One further background phenomenon or tendency to which it is wished to draw the reader's attention, concerns the change taking place in the orientation of the direction of the information transfer. It could be said that the traditional duty of the insured to inform the insurer about the risk is slowly being replaced, or at least complemented, by the duty of the insurer to obtain information i.e., by the duty of the insurer to inform himself ('le devoir de l'assureur de s'informer') about the needs of the client. The drafters of the Principles of European Insurance Contract Law have paid careful attention to this tendency and a step in this direction is provided for in Article 2.202 of the Principles where the insurer is given the duty to warn the applicant about inconsistencies between the cover and the applicant's requirements. These 'new' duties on the insurer itself to make efforts to obtain a clear picture of the insured risk are different from the efforts that insurers used to make by issuing the traditional questionnaire. In this latter case the information was sought after with

6) Directive (2004/113/EC) of 13 December 2004 implementing the principle of equal treatment between men and women in the access to and supply of goods and services (OJ L 373 of 21 December 2004, p. 37). 
a goal of serving the interests of the insurer (better risk-appreciation, more accurate risk differentiation). Here the insurer's duty to obtain information ('le devoir de l'assureur de s'informer') is imposed with the aim of procuring insurance cover that is better adapted to the needs of the insured. In a way one could say that by putting these information-gathering duties on the insurer (or his representative), the law is imposing a new obligation and liability on the insurer - namely an obligation with respect to the 'fitness for purpose' of the insurance coverage offered. This obligation, which is well know in the 'product liability' field, appears now to be expanding into the provision of services (especially into the financial services area).

An important aside can be made at this point, beginning with the observation that the duties of the insurer to obtain a good understanding of the needs of the client have often been formulated in the so-called 'codes' or 'rules of conduct'. It has already been mentioned in the text above how, under the present state of English law, strict legal rules concerning disclosure and misrepresentation are softened by several codes of practice. However, as is well known, outside English law too, these 'codes of conduct' are gaining both in importance and momentum. In this respect, particular mention can be made of the Markets in Financial Instruments Directive (MIFID) ${ }^{7}$ and especially to the 'rules of conduct' (les 'règles de conduite') that are laid down in this Directive with respect to transactions in financial instruments. Specific mention can be made of the well known 'Know Your Customer' rule. The MIFID rules of conduct apply to investment service providers, not insurers. But it is quite clear that the underlying principles of the MIFID rules of conduct will also indirectly affect the relation between insurer and insured, because even now they already apply to the relationship between the (independent) intermediary and his client under the Insurance Mediation Directive. The tendency, mentioned in the text above, to put a more active investigative duty on the insurer and/or the insurance intermediary can be seen as an illustration of the 'spill-over effect' that the 'Know Your Customer' rule is already having at this time on the insurance field.

\section{The Issues}

The core of the subject matter may now be returned to, and the rules in the Principles of European Insurance Contract Law dealing with the pre-contractual information duties of the applicant addressed. Let us start by giving a brief overview of the main questions, options or issues on which the drafters of the Principles, just as the drafters of any insurance contract, had to take a stand.

The first question was whether the drafters should adhere to the (old) system of a spontaneous obligation of disclosure on the part of the applicant or should they turn to the formula of a list of questions, the so-called questionnaire (le 'formulaire de déclaration du risque' as it is called in French law, or the 'Fragebogen', as is referred to in German).

\footnotetext{
7) Directive 2004/39/EC of the European Parliament and of the Council of 21 April 2004 on markets in financial instruments amending Council Directives 85/611/EEC and 93/6/EEC and Directive 2000/12/EC of the European Parliament and of the Council and repealing Council Directive 93/22/EEC, OJ L 145 of 30 April 2004, p. 1.
} 
Another question is whether the applicant must declare what he 'knows' or should he be expected to declare 'what he ought to know' (i.e., 'active or constructive knowledge'). The issue is a delicate one, given the fact that the 'ought to know' rule might be interpreted as putting an active duty of investigation upon the applicant.

Another question is how the issue of the imputation of the knowledge of the persons to be insured to the applicant should be dealt with.

Another question is whether the Principles have an explicit rule on the treatment of the declarations of the applicant that were not asked for.

Further, in a case where the applicant's declaration is discovered to have been inaccurate, should the insurer have the power to terminate the contract or should the law strive to induce the parties toward a continuation of the contract, albeit under an adapted tariff premium or other conditions?

Again, if an incorrectness or incompleteness in the description of the risk is discovered after a claim has been brought against the insurer, should then the insurer have the right to refuse coverage ('Alles oder Nichts-Prinzip') or would, where appropriate, a proportional reduction of the cover be the proper sanction?

In this last event, as well as insofar as concerns the previous issue (viz., continuation or discontinuity), will the degree of culpability of the applicant, in making the inaccurate disclosure, play a role, so as to differentiate the sanction according to whether the shortcoming was innocent, negligent, or fraudulent?

Finally, in a case where non-disclosure or inadequate disclosure is discovered on the occasion of the occurrence of an insured event, the question arises of whether the insurer should be allowed to refuse total or partial coverage even in the case where there is no connection between the undisclosed circumstance and the insured event? Or should the Principles follow the tendency of some recent legislations by introducing a requirement of causality or relevance between the non-disclosed fact or circumstance and the occurrence of the insured event?

Of course, many other (and broader) questions existed which had to be decided upon, either generally, i.e., with respect to the entire project, or specifically with respect to the duty of disclosure. Some examples of these may be given, without however aspiring at any degree of completeness.

Will the Principles deal with these issues in a mandatory way? The answer to this question is 'yes', for matters relating to mass risks (in the sense in which this term is used in the Internal Market Directives) where the Principles are mandatory (not absolutely mandatory, however, but rather semi-mandatory in the sense that the contract may derogate from the provisions as long as such derogation is not to the detriment of the policy-holder, the insured or the beneficiary). Should a distinction be drawn (as in the proposals of the Law Commission) between consumer risks (or Jedermann-Versicherung, or 'contrats de grande diffusion') and large business risks? The answer is that, as has been previously stated, the Principles adhere to the distinction between large risks and mass risks, and do not further differentiate between consumer risks and other ones. Another question is whether the issue of aggravation of risk and related duties of disclosure will be treated as a sort of prolongation of the original duty of disclosure into the further course of the contract. Here the answer is that in the Principles a different approach is taken, with the issue of risk aggravation being rather addressed in the context of the preventive duties of the insured (precautionary measures). 


\section{The Applicant's Pre-contractual Duty to Inform}

The essential rule in the proposed Principles as regards pre-contractual information duties is laid down in Article 2.101, which provides that when concluding the contract, the applicant shall inform the insurer of circumstances which he is or ought to be aware of and which are the subject of clear and precise questions put to him by the insurer.

The basic idea of this rule is quite clearly to subscribe to the system of 'the question method". As it is said in the (projected) comments to this article "it is usually more difficult for applicants to know what information is material to the risk than for insurers" and "such a rule (requiring a 'questionnaire') is likely to avoid unnecessary transaction costs and subsequent disputes".

But in order to avoid the insurer limiting itself to putting broad questions that result in reintroducing some kind of duty of spontaneous declaration, a requirement is imposed that the questions be clear and precise. The objective is to make it impossible for the insurer to postpone the real evaluation of the risk till the moment where the insured event occurs. The rule laid down in Article 2.101 must thus be understood as follows. The applicant must fulfill his information duty by answering the questions put to him by the insurer. Thus 'full and honest' disclosure is required. The Principles make no difference between incomplete information ("omissions") and inaccurate information ("misrepresentations"), inter alia because it was considered that in some cases the distinction may be difficult to draw. ${ }^{8}$

The questions must be clear and precise. If they are not, the applicant will not be subject to any sanction for not answering such questions.

While answering the questions, the applicant must declare all the circumstances that he knows or ought to know about (or to use the exact wording of the text, "the circumstances that he is or ought to be aware of"). This rule gives rise to the delicate question as to what is the level of the knowledge that a person ought to have? Is the test for the presence of 'constructive knowledge' objective or should individual characteristics or qualities of the applicant be taken into account? Under United Kingdom law, for instance, a distinction is made between persons seeking insurance in the course of a business and so-called consumers, but as has already been pointed out, the Principles of European Insurance Contract Law do not make this distinction. The projected comments to Article 2.101 explain that although the Principles do not make such a distinction, courts applying this provision should recognise the reality that some kinds of applicant can be expected to know more than others. For example, a medical physician applying for accident cover or a fireman applying for house cover. However the rule is intended to be an 'objective rule'. The question then arises whether under such rule the applicants have some kind of duty to check, enquire or investigate facts that are not in their actual knowledge or of which they are uncertain? Do applicants have a duty of investigation that enables them to better inform the insurer ('l'obligation de s'informer pour informer')? Here, the projected comments make it clear that applicants are not expected to make investigations except when

\footnotetext{
8) An example illustrating the delicacy of the distinction is the question whether the applicant who admits to having incurred four previous convictions, whereas in reality he incurred five of them, is guilty of a misrepresentation or of ommitting part of the information to be given.
} 
explicitly asked for but that applicants are expected to make honest statements. Applicants, it is said, are not allowed to turn a blind eye to the possibility of information that could be adverse to their application.

The relevant circumstances that must be described are those prevailing at the time the insurer reaches a decision to accept the application. In this connection, it is understood that, if the circumstances change in a material way between the time the application is submitted and the time the contract is concluded, the applicant is obliged to give the insurer notice of any such change, of which the applicant is or should be aware.

In accordance with what has been done in several national legal systems, the Principles introduce a gradation of sanctions that is based on a number of distinctions.

A first distinction which will play a role relates to the moment where the insurer becomes aware of the applicant's violation of his duty of disclosure. When the insurer discovers the true state of affairs other than in the circumstance of where an insured event has taken place, the question will be about whether and how the contract will proceed in the future. However, more often than not, the insurer will discover the applicant's breach on the occasion of the occurence of an insured event. As has been indicated above, that moment appears to be the 'moment suprème' in the relationship of the contracting parties, where the insurer effectively learns the true nature of the risk or where he will take the necessary steps to discover it. In such an event, not only will the question of the future fate of the contract arise, but a first issue will be how to handle the insured event, and more precisely the issue of if and to what extent the claim will be honoured by the insurer, given the discovery of the policy-holder's earlier breach of his duty of disclosure.

Both with respect to the insurer's decision as to whether or not to continue with the contract and (as the case may be) as to how to modify it, as well as with respect to the questions of whether and to what extent the claim will be covered, two other distinctions arise.

One distinction relates to the degree of culpability with which the applicant has broken his duty of disclosure. The major distinction is the one between fraudulent breach and non-fraudulent breach. In the case of non-fraudulent breach of contract, a further distinction is made between a so called 'negligent breach' and what the Principles term an 'innocent breach'.

Another distinction relates to the attitude which the insurer would have adopted and the decision which the insurer would have taken, had he known the true state of affairs at the moment of the conclusion of the contract. The question is to know whether in such hypothetical situation the insurer would have refused to enter into the contract (a hypothesis referred to hereinafter for the sake of brevit, as that of an 'uninsurable risk') or whether he would have done so, albeit at a higher premium or on different terms.

A final distinction in the treatment of the consequences of breach of the duty of disclosure relates to the question whether or not the insured event is caused by an element of the risk which is the subject of the inadequate disclosure by the applicant. This last distinction being the most revolutionary one when compared with traditional insurance law, will form the focus of more attention below.

The summa divisio is the one between the fraudulent breach (dealt with in Article 2.104) and the other cases, where the breach is innocent or negligent (dealt with in Articles 2.102 and 2.103). Starting with the latter category, the first hypothesis is that 
the discovery of the (innocent or negligent) breach takes place other than in the circumstance of the occurrence of an insured-against event. Article 2.102 proclaims as a general rule that when the policy-holder is in breach of his duty of disclosure under Article 2.101 the insurer shall be entitled to propose a reasonable variation of the contract or to terminate the contract. It is thus up to the insurer to choose. However, if the following conditions are fulfilled, the Principles restrict the choice of the insurer. If the policy-holder is in innocent breach of his duty, the insurer will be allowed to terminate the contract only where he proves that he would not have concluded the contract, if he had known the information concerned.

The procedural aspects of the choice are specified throughout Article 2.102. The Principles do not require the insurer to notify the policy-holder that it has become aware of an incident of non-disclosure or that the question is under review. But it has to make up its mind within a short period of time. Where it is given a choice between termination or adaptation of the contract, the insurer has to make a decision by giving written notice of its intention, accompanied by information on the legal consequences of its decision, and it must do so within one month after the breach becomes known or apparent to him.

If the insurer chooses to terminate, termination shall take effect one month after the written notice has been received by the policy-holder. If the insurer proposes a variation, the contract shall continue on the basis of the variation proposed in the manner and on the moment as agreed upon by the parties. However the policy-holder may reject the proposal by a written notice of rejection, within one month, without having to give any motivation or justification. In such an event, the insurer shall be entitled to terminate the contract within one month of the receipt of written notice of rejection. Here again termination will take effect after one month.

If the policy-holder does not react within the permitted time, variation will take place in accordance with the agreement of the parties. Although the text does not say so explicitly, the non-respect of the one month time limits leads to loss of rights (estoppel) for both the insurer and the policy-holder.

In the (more common) event that the non-disclosure is discovered after an insured event has taken place, and more generally in the event of an insured event occurring before the variation or termination of the contract takes effect, again distinctions are made according to the degree of culpability of the insured and according to the (un-)insurability of the true nature of the risk. In this case too, the future fate of the insurance contract is subject to the general rule laid down in Article 2.102. The next question is how to deal with the coverage of the insured event.

If the policy-holder is in innocent breach of his duty, the insurance money is payable, and that remains so even in the case of an 'uninsurable risk' (thus of the insurer would not have entered into the contract, if he had known the true situation).

If the policy-holder is in negligent breach of his duty, a further distinction must be made between the hypothesis of an uninsurable risk (i.e., where the insurer proves that he would not have insured at all), and the case where the insurer would have insured the risk but only at a higher premium or on different terms. In the first case no insurance money has to be paid, whereas in the second one insurance money shall be payable proportionally or in accordance with such terms, under which the insurer would have covered the risk. Both rules (regarding non-payment in case of uninsurability in the one case, or proportional reduction or adaptation in the other case) apply 
only if the insured event is caused by an element of the risk which is the subject of negligent non disclosure/misrepresentation. It is thus here that our Principles introduce the remarkably new causality requirement, which has been absent from the approach of traditional insurance law.

Whenever some of the conditions laid down in Articles 2.101 and 2.102 are not fulfilled by the insurer, the insured will be able to rely on an exception to the insurer's rights. Examples are the situation of where the insured was not aware or did not have to be aware of the true circumstances of the risk, or the case where the questions were not clear and precise; the situation of where the written notice of the insurer came too late or was not accompanied by the proper information; the situation of where the policy-holder was innocent and not negligent; and the situation of where the insured event was not caused by an element of the risk.

Over and above this, Article 2.103 allows the insured to rely on four additional exceptions to the insurer's rights. The underlying idea is here that whereas the applicant must answer the questions, in a number of situations the insurer will nevertheless lose the right to impose sanctions for the applicant's failure to answer them.

The first case is where the insurer concludes the contract even though a question remains unanswered or the information supplied by the applicant is obviously incomplete or incorrect. The effect of this is that, if the insurer concludes the contract nonetheless, the answer to the question must be considered to have been immaterial to the insurer's decision or so marginal that the insurer was willing to assume the risk whatever the answer.

The second situation mentioned in Article 2.103 is where missing or wrong information given by the applicant is not material to a reasonable insurer's decision either to enter into the contract or else to do so at the agreed terms. Under the rule in the Principles, the materiality of a particular item of information is not proven by the sole fact that the insurer asks for it. One can say that in the Principles, the fact that the insurer has put a question about an issue, creates a presumption of 'materiality' of the issue. The Principles refer to "a reasonable insurer's decision". The question arises of what a reasonable insurer is. The reasonable insurer is like the reasonable man, a myth popular with legislators. The term implies that the reference is to an objective standard, and thus not the individual insurer concerned.

At this stage the (draft) comments say that if it is difficult to say what a reasonable insurer would decide, it is at least possible to say what no reasonable insurer would consider as immaterial.

The third case in which the insurer loses its right, is where it leads the policyholder to believe that the information does not have to be disclosed. The Comments explain that what is envisaged is e.g. the case where the applicant answers the insurer's question with the assistance of an employee or representative of the insurer. If the representative advises the applicant erroneously that a particular fact - which is one that the insurance market would regard as material - does not have to be mentioned, and the applicant reasonably relies on that advice, the particular insurer is 'estopped' from pleading non-disclosure on the part of the applicant. In other words, the insurer, through the representative, is, in such a case, deemed to have waved the disclosure of the information in question and is not entitled to the same.

The final instance where the absence of an answer to a question from the insurer cannot be held against the policy-holder is where the information is known or ought to 
be known to the insurer. If material information is already known to insurers, there is a rebuttable assumption that they conclude a related contract of insurance in reliance on their own knowledge rather than what is said or not said about the matter by the applicant. This rule must also apply to what the insurer ought to know. For insurers, the imputation of knowledge should not extend purely to paper based records but the imputation should extend to information which is readily accessible and thus to in-house computer data, (notably records) and also data compiled collectively with other insurers.

It is now proposed to look at the situation where the insurer has been led to conclude a contract by the policy-holder's fraudulent breach of Article 2.101. As far as the concept of fraud is concerned, reference is made to Article 4.107 (2) of the Principles of European Contract Law. Article 4.107(2) states that a party's representation or non-disclosure is fraudulent if it is intended to deceive.

Under Article 2.104 of the Principles, the insurer has in fact the choice between three possible reactions: either he can choose to do nothing and the contract goes on, or else he can choose one of the possibilities in Article 2.101 (variation or ex nunc termination) or else he can choose to avoid the contract.

It is to be noted that the Principles of European Insurance Contract Law do not require the nullity of the contract, but give the insurer the right to avoid, a right which he chooses whether to exercise or not. If the insurer chooses to avoid the contract, the effect is retroactive. In accordance with Article 4.115 of the Principles, avoidance gives either party the right to claim restitution of whatever it has supplied. Article 2.104 of the Principles derogates from this rule insofar as it prescribes that the insurer is to be entitled to retain the premium. In the draft comments to this Article it is said that Article 2.104 is inspired by the goal of deterrence. The fraudulent applicant must not be allowed to think "if the fraud is successful, then I will gain and if it is unsuccessful (unless there has been an intervening loss) I will lose nothing."

Fraud that has no effect on the insurer's decision (because the information is immaterial or because the insurer was aware of its falseness) does not have any consequences.

In the event of fraud, as in other situations, the insurer is required to reach a decision within a certain period of time. In cases of fraud, the period is three months instead of one month.

Under Article 1.205, policy-holders are not obliged to supply additional information but if they do so, it must be accurate and complete.

\section{Change of Risk Level}

When the the Principles of European Insurance Contract Law turn to the issue of the change of the level of risk, they present a slightly different face and style. Characteristic of the way in which the Principles deal with the change of risk level is first the place where the rules on change of risk level are to be found. They are not dealt with under the chapter on the obligations of the insured party, but under the chapter on the risk insured. Also the tone is different. Here the rules are not like mandatory rules but rather like rules that seek a compromise between party autonomy and protection of the policy-holder. However, with respect to the issue of reduction of risk, the Principles do not give room to such party choice. 
The question is why there is this change of style. It is the view of the present writer that there are several reasons for this. Insofar as concerns risk aggravation which occurs in the course of the contract, one does not find oneself in the pre-contractual sphere but rather right in the middle of the performance of the contract. Also, here we touch upon an issue that goes to the very essence of insurance. One might expect that an insurer who agrees to cover the risk, must anticipate not only the risk, but also the changes in the risk that might take place in the course of the contract, and that it is not to be ruled out that an insurer assumes both the risk and the changes in the level thereof. Therefore, no mandatory rule about adjusting the terms of the contract is required and there is room for a model of regulation that relies on contractual arrangements. One might also observe that the issue of change, and especially aggravation of risk is a matter where different insurance cultures react differently. Indeed the way in which change of risk is treated offers another example of a different approach between civil law and common law tradition, or, to employ the terminology of Michel Albert, between the Alpine and Maritime Insurance traditions ${ }^{9}$. The common law tradition seems to be rather wary of cancelling contracts in the middle of the short insurance period which is usual under the common law, whereas cancellation is more normal in the tradition of long term contracts found in the continental insurance tradition, Under the Anglo-Saxon approach (which is also the approach found in the new Dutch insurance law), it is up to the insurer to protect himself against aggravation of risk, and the legislation has no function other than that of ensuring some basic protection to the policy-holder.

Without leaving the matter to general contract law, the Principles of European Insurance Contract Law leave to the parties (and thus, more often than not, to the insurer) the decision as to whether or not to make provision for situations of change in risk level, . But the objective of consumer protection is not abandoned. Therefore Articles 4.101 and the articles which follow it provide for the outer limits of the freedom of contract and for some basic rules of protection. The result of this approach is that the Articles are drafted in the 'if' style. If the parties decide to have rules in the cases of aggravation of the risk, they have to adhere to certain rules. These rules may be briefly recounted here.

It appears from Article 4.201 that if the parties want to have a clause governing aggravation of risk, the definition of such 'aggravation of risk' is not entirely left to their discretion. One possibility which the drafters of Article 4.201 envisaged consisted of linking risk aggravation to a questionnaire (to be sent by the insurer to each client) about the state of the risk at the outset of the contract. This approach, considered to be too regulatory, was abandoned. Instead, Article 4.201 now limits itself to referring to the concept of materiality (as used in the context of pre-contractual disclosure). More precisely, an aggravation must be material (to the evaluation of the risk) either because of its magnitude and/or because of its probability. Article 4.201 also requires that the aggravation must be "of the kind stipulated in the insurance contract". The idea is here that the policy-holder must be made aware of his obligation through the insurance contract.

In the same 'if' style, Article 4.202 (1) stipulates that if the contract contains a clause on notification, then the notification can be required to be given by several

9) Cfr. Albert [2], p. 181; Albert [1] p. 315. 
persons (viz., the policy-holder, the insured, or the beneficiary, as appropriate) provided that the person obliged to give notice was aware or should have been aware of the existence of the insurance cover and of the aggravation of the risk. If under the terms of the contract, notice must be given within a period of time, the period of time should be a reasonable one (Article 4.202 (2)).

The Principles do not impose a rule as to what sanction can be imposed upon the policy-holder who has failed to fulfil his duty of notification. Article 4.202 (3) does not exclude various sanctions like a proportional reduction of cover or payment of extra premium. What Article 4.202 (3) says is that a clause may not decree loss of all rights on the sole ground of the breach of this duty unless the loss was caused by the aggravation of the risk.

One possibility is that a contract provides that in case of aggravation of risk, the insurer shall be allowed to terminate the contract. The Principles recognise that an insurer may have good reasons to do so, but the Principles submit the insurer's right to do so to a number of restrictions. A written notice is required to be given to the policy-holder within one month of the moment when aggravation was known or apparent to the insurer. Cover is to expire one month after termination, and only immediately if the policy-holder was in intentional breach of his duty. If an insured event occurs before cover has expired, then insurance money is to be payable. However, if the insured event is caused by the aggravated risk, and if the aggravation is one of which the policy-holder was aware/or should have been aware prior to the event, then the proportionality rule must apply. This means that there can only be a proportional reduction of the insurance payment if the insurer would have insured at a higher price. Only in the hypothesis of an uninsurable risk, can there be an entire loss of cover.

Without being explicit about what can be considered as a reduction of risk level, the Principles nonetheless prescribe rules with respect to a contractual regime. Here, less choice is left to the parties. If there is a material reduction of the risk, the policyholder is to be entitled to request a proportional reduction of the premium for the remaining contract period. If the parties do not agree on a proportionate reduction within one month of the request being made, the policy-holder is to be entitled to terminate the contract by written notice given within two months of the request being made.

\section{References}

1. Albert, M.: Capitalisme contre capitalisme, Paris, Seuil (1993)

2. Albert, M.: L'avenir de l'assurance: modèle alpin ou modèle maritime? Risques. Les Cahiers de l'Assurance, p. 181 (1991)

3. Basedow, J., Fock, T.: Europäisches Versicherungsvertragsrecht, Band I, Mohr Siebeck (2002)

4. Cousy, H.: Le Spleen de Paris and the Art of Harmonization and Restatement, in: Essays on Tort, Insurance, Law and Society in Honour of Bill W. Dufwa, Vol. II, Stockholm, p. 355 (2006) 